\title{
ALIGNING LEARNER CAPABILITIES TO INDUSTRY - A RESEARCH SNAPSHOT
}

\section{Amber Paterson}

Otago Polytechnic's aim is to produce the country's most employable graduates. The nature of work is changing globally, particularly in our COVID-19 affected world. Many people are now working in work environments that differ markedly from what they were before. Flexibility and fluidity to move across workplaces and different ways of working is vital.

\section{BACKGROUND}

Learner Capabilities are also known as transferable skills, soft skills, twenty-first-century skills or work-ready skills. They are a set of skills that can be used across a range of jobs. A nurse and a retail assistant need to have interpersonal skills. An engineer and a teacher both need critical thinking skills. A builder and a hairdresser both need the ability to solve problems. Transferable skills are developed throughout a person's lifetime through experiences at work, socially, in the community and through study.

The Learner Capability Framework (LCF) was first used in 2017 at the Otago Polytechnic's Auckland International Campus. From 2018 its implementation in certificate, diploma and degree programmes has continued through our Dunedin campus. A web-based tool called iamcapable, which is used by learners to upload evidence of their work-ready capabilities, was instigated in 2019. In the first semester of 2019 the LCF and usage of iamcapable was implemented in five diploma and degree programmes, which grew to a further 25 programmes in the second semester. By March 2020, 12 more programmes had embedded both the LCF and iamcapable in their programmes. This number has continued to grow through 2020 and 2021.

\section{AIM}

This research snapshot summarises research that has been undertaken on how Learner Capabilities (work-ready skills) are important in study and in the workforce.

\section{RESEARCH}

A major research project undertaken by Otago Polytechnic staff on Learner Capabilities was launched in 2018. There was a particular focus that year on what employers ranked as their top ten capabilities for their particular area of industry. Over the subsequent two years, further research was undertaken with alumni and current students and staff to assess what capabilities were important in their areas of study and work. This analysis snapshots the findings of these aspects of the research project and compares our findings with research undertaken elsewhere. This snapshot includes quotes from current students, alumni and staff about their experiences. (These comments are unreferenced as the full research document is currently at print.) $)^{i}$ 
During this research, the following groups were interviewed. Employers were initially interviewed to develop the Employer Priority Index. Following on from this, and using the employer index, the Otago Southland Employers Association, Kokiri Training Centre, current students, alumni (who had graduated within five years) and current Otago Polytechnic staff who had been using the LCF, were all interviewed.

Through an analysis of relevant websites we found a number of transferable skills that are similar to the LCF, and that directly correlate with our research at Otago Polytechnic. It is reassuring for us to know that our framework and programmes are aligned with employers' needs and industry practices.

The website Seek has identified a set of core transferable skills that people need in employment (Seek, n.d.). These are:

- Organisational skills (including creativity and time management)

- Communication skills (verbal, both written and oral)

- People skills (interpersonal skills)

- Teamwork (including critical thinking and problem solving).

"When you start working in an organisation the main thing is your communication with your colleagues/boss/customer." (business alumnus)

TradeMe have also listed their top ten list of most wanted transferable skills:

- Adaptability - being willing to make changes and be flexible in one's ways of working

- Growth mindset - being willing to better yourself and learn

- Communication

- Problem solving

- Emotional intelligence - recognising your emotions and those of those around you to assist with building positive relationships with others

- Creativity

- Cultural awareness

- Leadership

- Focus mastery - in a busy office or working from home there are many distractions: focus mastery is the ability to tune out the distractions around you

- Persuasion - the ability to persuade others that your ideas are worth pursuing.

"The lecturers in the BCA programmes really helped me identify my potentials ... during project-based learning they helped me identify my capability and what I could be doing in the future." (culinary arts alumnus)

Careers NZ emphasise the importance of transferable skills and have identified seven essential skills for the workplace (Careers.govt.nz, 2020):

- Positive attitude

- Communication

- Teamwork

- Self-management

- Willingness to learn

- Thinking skills (including thinking critically and problem solving)

- Resilience

Transferable skills extend across all walks of life, all kinds of vocations and all stages of the career path. When comparing transferable skills across these three employment websites we begin to see a trend, with the same skills popping up on all three lists. These include communication, teamwork, critical thinking, creativity and personal organisation. 


\section{OTAGO POLYTECHNIC RESEARCH}

In 2018 many lecturers headed out into industry settings to interview employers about the capabilities that are regarded as the most important in their fields. They showed the employers the full list of 25 capabilities (now 26) on the LCF and asked them to rank them from one to ten in order of importance. The employers' fields or work types were amalgamated into clusters and the data was then analysed in these clusters.

During the various stages of the research, it became clear that there were commonalities across the different clusters.

"I think for me, the prime selection would be if you were going to be a good team fit - that is why I have put 'displays effective interpersonal behaviour."' (visual arts employer)

Across all the study area clusters we found that, out of the 25 offered, employers valued four capabilities the most highly (in order of importance):

I. Works in teams

2. Solves problems

3. Communicates effectively verbally

4. Organises effectively.

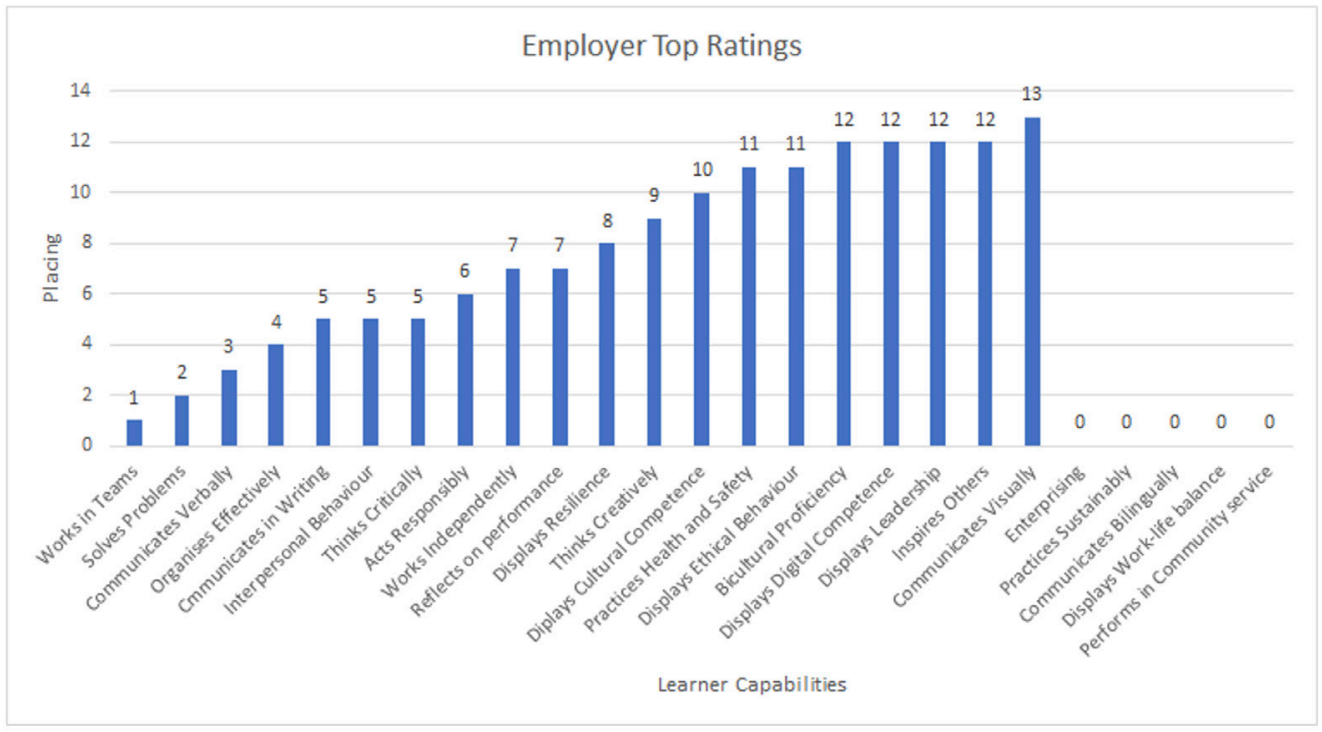

Figure I. Employer top ratings.

Similarly, having questioned alumni in a variety of areas, we found that they ranked the following as most important:

I. Communicates effectively verbally

2. Displays positive interpersonal behaviour and independence

3. Works in teams

4. Communicates effectively in writing. 


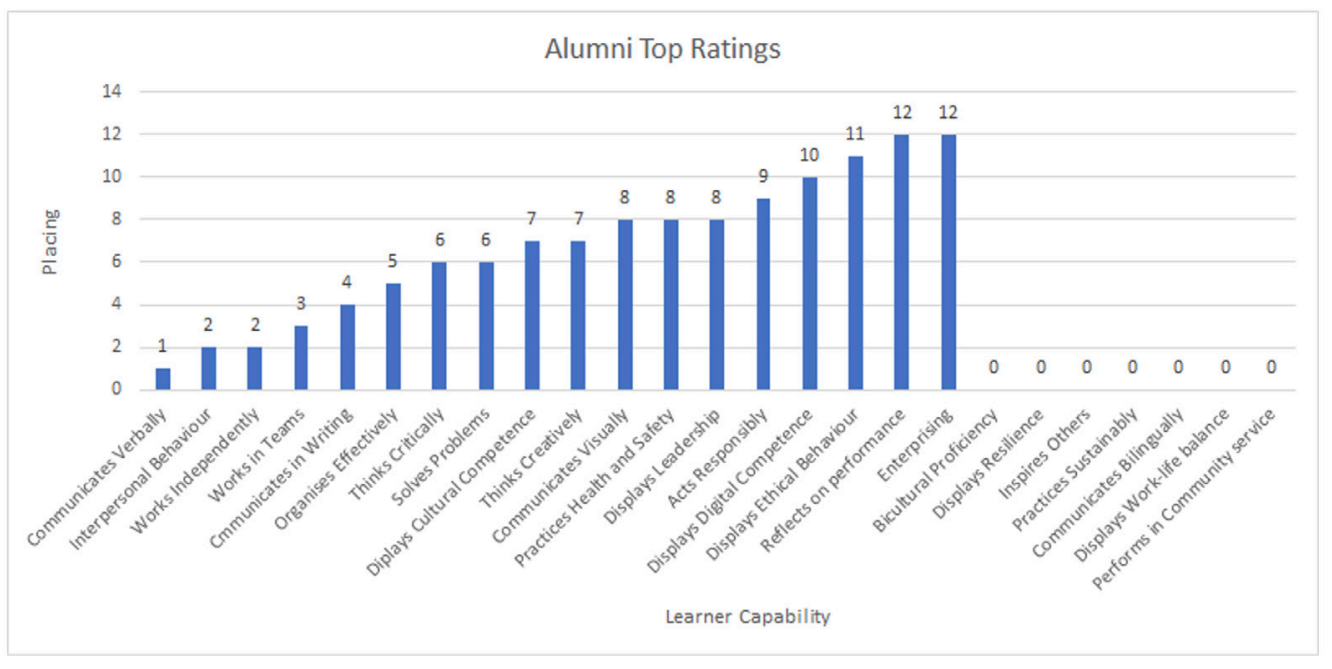

Figure 2. Alumni top ratings.

When we analysed the data more closely across employers and alumni, four capabilities emerged as commonalities:

I. Organises effectively

2. Communicates effectively verbally and works in teams

3. Displays positive interpersonal behaviour

4. Solves problems.

"If you communicate verbally, you will build relationships, you will build contacts, you will do a lot, you will move forward very effectively." (quantity surveying employer)

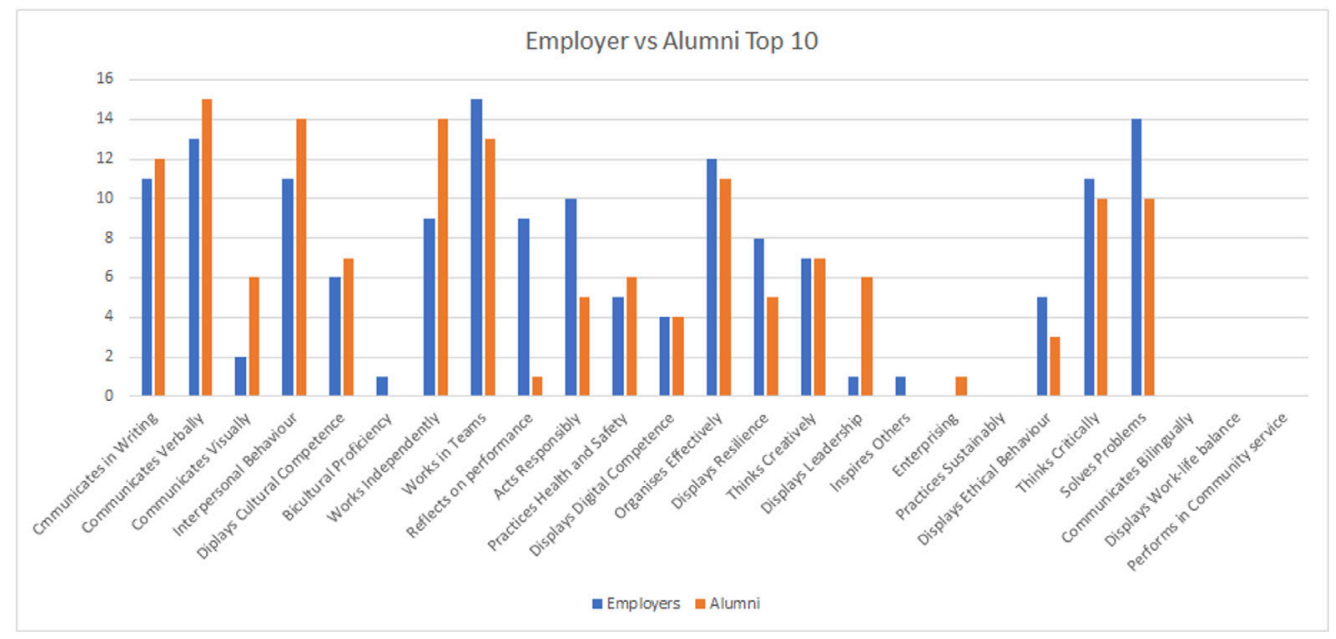

Figure 3. Employer vs alumni top 10. 


\section{IMPLICATIONS}

When an analysis was undertaken of the Learner Capabilities that individual Otago Polytechnic programmes had chosen as their core focus capabilities, we found that four factors - "communicates effectively verbally," "works in teams," "solves problems" and "communicates effectively in writing" - were most commonly chosen by teaching staff. This indicates that the capabilities we focus on in our teaching programmes are also identified as key by our alumni and by employers. This suggests that, overall, there is a good match between teaching and learning, on the one hand, and employment, on the other, and that this correlates closely with the capabilities that Seek, TradeMe and Careers NZ have identified.

However, while most alumni questioned stated that they felt capability-ready, they would have liked more practical, real-world scenarios in the classroom, as well as help with seeking work and networking opportunities.

While this project has now concluded, further research in this area is desirable including further investigations into increasing the number of undergraduate certificate and diplomas and the long-term impact and usage of the Learner Capability Framework and the web-based tool iamcapable.

Amber Paterson is a Learning and Teaching Specialist at Otago Polytechnic. Amber completed her Master of Education in 2017, when her research focus was on educational assessment. Amber was a primary school teacher for 19 years, with the last 12 years as deputy principal at a school on the Taieri Plain, Otago.

(10 https://orcid.org/0000-0002-4337-5334

\section{REFERENCES}

Careers.govt.nz (2020, February 26). Skills employers are looking for. https://www.careers.govt.nz/plan-your-career/get-ideas-foryour-career/skills-employers-are-looking-for/

Seek. (n.d.). Transferable skills checklist. https://www.seek.co.nz/career-advice/article/transferable-skills-checklist

TradeMe (n.d.). The top 10 soft skills employers are looking for in NZ. https://www.trademe.co.nz/c/jobs/article/the-top-10-soft-skillsemployers-are-looking-for-in-nz

i Otago Polytechnic Learner Capability Research documentation is available at https://issuu.com/oplearnercapability. 